\title{
Implementação da gestão de portfolio de novos produtos: um estudo de caso
}

\author{
Paulo A. Cauchick Miguel EPUSP
}

\section{RESUMO}

Um dos aspectos relevantes no desenvolvimento de novos produtos é uma seleção adequada de projetos de desenvolvimento, visando uma tomada de decisão mais eficaz, o que a literatura usualmente denomina de gestão de portfolio. Nesse contexto, este trabalho objetiva apresentar a implantação da gestão de portfolio em uma empresa de processo contínuo, sendo uma das líderes no segmento que atua na América Latina. 0 trabalho adota o estudo de caso como abordagem metodológica, cujas evidências foram coletadas de diversas fontes. Os resultados indicam que a implementação trouxe maior facilidade na seleção dos projetos baseada em uma carteira representativa dos novos produtos, bem como proporcionou um maior rigor na tomada de decisão, sendo estes aspectos importantes identificados na literatura. $\mathrm{O}$ trabalho de campo demonstrou a existência de prática relevante em gestão de portfolio, suportado pela teoria vigente, embora limitado pela investigação de caso único.

\section{PALAVRAS-CHAVE}

Gestão de portfolio, desenvolvimento de produto, estudo de caso.

\section{A case study on portfolio management implementation for new products}

\begin{abstract}
One of the relevant aspects of new product development is the adequate choice of development projects aiming at having a more effective decision making. The literature usually named that as portfolio management. In this context, the objective of paper is to demonstrate an implementation of portfolio management in a company that is one of the leaders in its business in Latin America. Case-based research is adopted as the methodological approach, from which data were collected from various sources of evidence. The results point out that the implementation has brought more facility to select product development projects as well as more rigour in the decision making process. The article concludes that the field research demonstrated a relevant practice of portfolio management, supported by the current theory, despite the limitation of a single case study.
\end{abstract}

\section{KEY WORDS}

Portfolio management, product development, case study. 


\section{INTRODUÇÃO}

Atualmente, para as empresas que têm o desenvolvimento de novos produtos como estratégia, é imperativo que estas tenham condições de colocar seus produtos no mercado com maior rapidez, qualidade e custos. As empresas geralmente possuem um processo para desenvolver seus produtos, mesmo que este não seja claramente explicitado. Mesmo assim, alguns autores (CLARK; WHEELWRIGHT, 1993; COOPER, 1993) enfatizam a necessidade de essas empresas melhorarem o processo de desenvolvimento, seja gerenciando sua carteira de desenvolvimento, alterando sua estrutura de trabalho, ou utilizando métodos e técnicas que facilitem o desenvolvimento de um novo produto. Isto possibilita que as empresas desenvolvam melhores produtos, de forma mais eficaz e eficiente, ou seja, de modo mais competitivo.

Um dos aspectos importantes nesse sentido é o que se entende como gestão de portfolio, que consiste no gerenciamento do conjunto de projetos associados aos objetivos estratégicos da organização de forma compatível com os recursos disponíveis para sua realização. Uma empresa tem geralmente diversas possibilidades de desenvolvimento de novos produtos, direcionados para vários mercados, e tem que decidir quais produtos serão desenvolvidos em determinado período. A Figura 1 ilustra diversos mercados que se deseja atingir ( $A, B, C$ e D) para os quais define-se um conjunto de produtos, ilustrados pelos projetos $\mathrm{C} 1$ a $\mathrm{C} 6$, que se encontram em diferentes estágios de desenvolvimento.
Nas últimas décadas, a literatura sugere uma série de termos gerais como "gestão de portfolio" (de novos produtos), termo que, em estudos mais antigos, é denominado de "seleção de projetos" (DANILA, 1989). Mais tarde, o termo gestão de portfolio surgiu como sendo "priorização do desenvolvimento de produto" (TATIKONDA, 1999; COOPER et al., 2000) e, mais recentemente, como "gestão de múltiplos projetos" (DOOLEY et al., 2005). Na verdade, os últimos anos têm demonstrado um grande interesse no estudo desse tema e estudos comparativos (como os de benchmarking de COOPER et al., 1997a; 1997b) têm apontado a gestão de portfolio como uma das áreas mais limitadas no desenvolvimento de novos produtos.

Nesse contexto, o objetivo do presente trabalho é demonstrar uma implantação da gestão de portfolio para desenvolvimento de novos produtos. $\mathrm{O}$ trabalho pretende responder à questão de como ocorre a implementação da gestão de portfolio na empresa investigada, sua relação com o processo de desenvolvimento de novos produtos, além de identificar a associação entre as decisões (de implementação) tomadas com a literatura. Embora fosse importante, o presente estudo não tem o propósito de geração ou refinamento da teoria associada à gestão de portfolio, mas de oferecer uma contribuição empírica. $\mathrm{O}$ trabalho foi conduzido em uma empresa fabricante de produtos para o setor de embalagens, sendo uma das líderes na América Latina, com um terço da fatia de mercado. $\mathrm{O}$ trabalho adotou como abordagem metodológica o estudo de caso, com base na literatura (YIN, 1994;

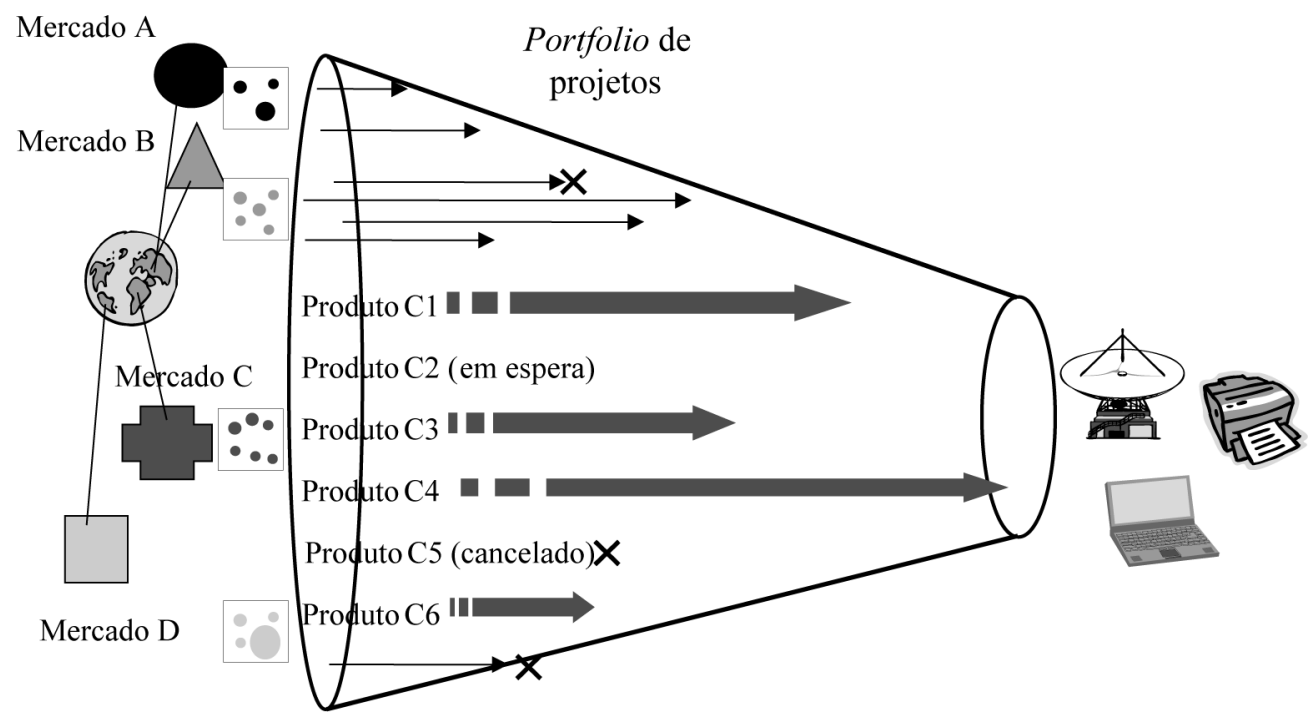

Figura 1: llustração de um Portfolio de Produtos e Projetos.

Fonte: Rozenfeld et al., 2006. 
VOSS et al., 2002). A escolha justifica-se porque o contexto é relevante, em função da recente implementação da gestão de portfolio, que objetiva uma maior facilidade e rigor na definição da carteira de projetos a serem desenvolvidos. O autor atuou como observador passivo utilizando-se de várias fontes de evidência, detalhadas mais à frente. Espera-se que o presente trabalho contribua com a discussão empírica sobre a implantação da gestão de portfolio, pois esse é um tema relativamente pouco explorado no país. Para cumprir seus objetivos, o trabalho primeiramente estabelece o referencial teórico do trabalho, seguido pelos métodos e técnicas adotados, resultados alcançados e, finalmente, suas conclusões.

\section{REFERENCIAL TEÓRICO}

Um portfolio para desenvolver novos produtos é associado a uma perspectiva de natureza estratégica nas organizações no âmbito da gestão de desenvolvimento de produtos. A
Figura 2, proposta por Cooper et al. (1998), ilustra a relação entre o portfolio de novos produtos e o processo de desenvolvimento destes produtos.

A perspectiva estratégica compreende o alinhamento das metas e objetivos da empresa, considerando as particularidades do seu negócio, com o conjunto de projetos em desenvolvimento, relacionando esse conjunto com a capacidade da organização em desenvolver novos produtos. Além disso, é também uma tentativa constante de articular as necessidades do mercado com as competências tecnológicas e organizacionais, permitindo continuidade no negócio da empresa (CHENG, 2000). Nesse caso, o termo que é geralmente empregado na literatura é "gestão de portfolio" (conforme usado por MEYER, 1997; COOPER et al., 1997a; 1997b; 2000), pois existe uma preocupação nas organizações em estabelecer o conjunto de projetos que deve ser desenvolvido.

A perspectiva de natureza organizacional é voltada para a condução de projetos específicos, ou seja, é responsável pelo desenvolvimento propriamente dito, conduzindo e

PORTFOLIO

GESTÃO DO DESENVOLVI/TO

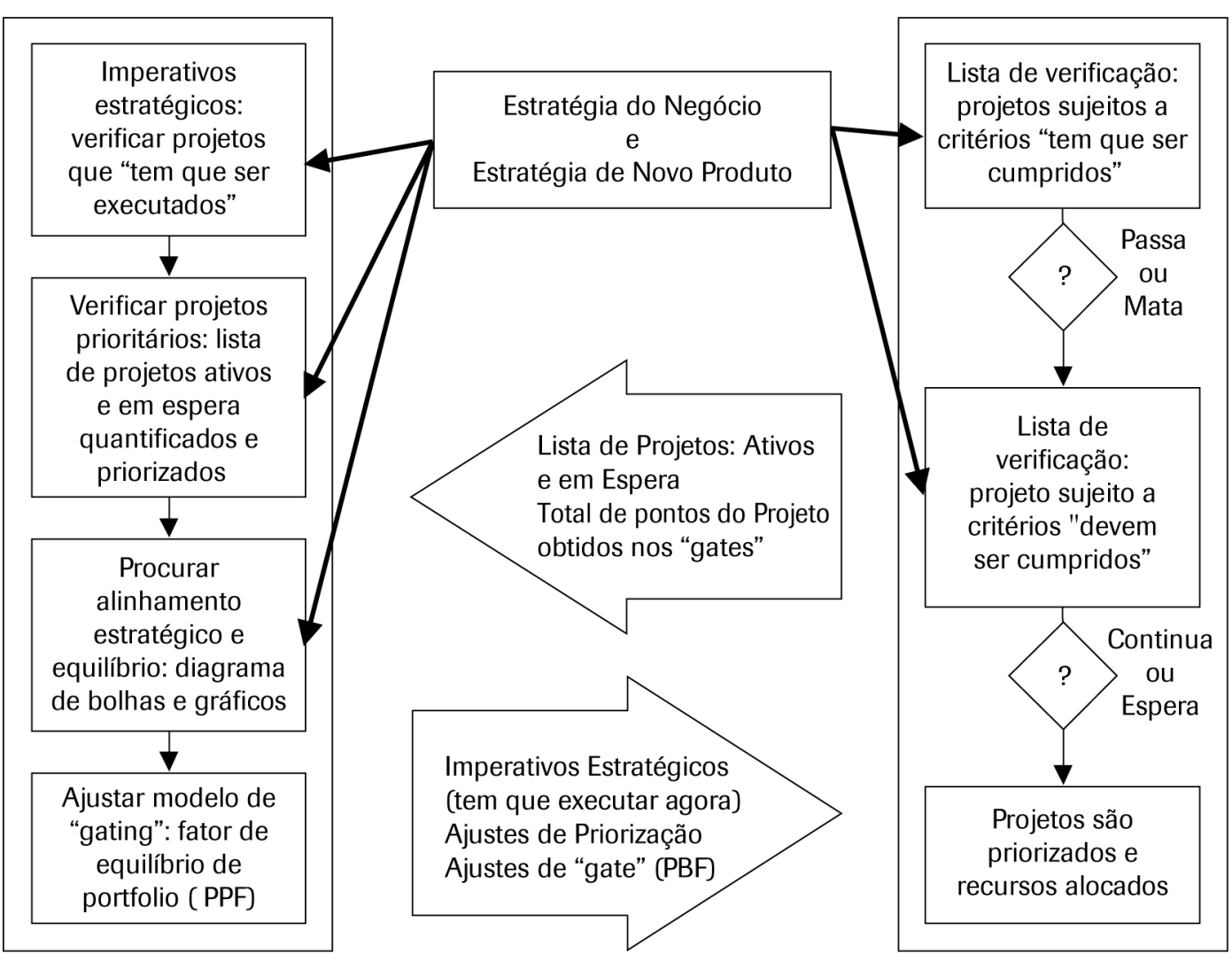

Figura 2: Gestão de Portfolio e do Desenvolvimento de Produtos.

Fonte: Cooper et al., 1998. 
gerenciando o projeto de um novo produto. Essa perspectiva concentra esforços não somente no processo em si, mas também na utilização de métodos e técnicas que suportem este processo, visando a sua organização. Nesse sentido, existem diversos modelos de desenvolvimento que buscam representar este processo, destacando-se dentre eles a estrutura do funil de Clark e Wheelwright (1993) e a estrutura genérica do stage-gate, proposta por Cooper (1993). Outras variantes também podem ser encontradas na literatura (e.g. em DUNCAN, 1996).

De acordo com Cooper et al. (1998), a gestão do portfolio é um processo de decisão dinâmico, pelo qual um conjunto de projetos de novos produtos são constantemente atualizados e revisados. Nesse processo, novos projetos são avaliados, selecionados e priorizados. São verificados aqueles projetos que estrategicamente são vitais para serem executados, seja pela vertente tecnológica ou mercadológica (representada no lado esquerdo na Figura 2).

O processo de decisão de portfolio engloba uma série de outros processos de tomada de decisão. Inclui revisões periódicas do portfolio de todos os projetos, ou seja, visualiza-se todo o conjunto de projetos, comparando os projetos entre si. Também tomam-se decisões do tipo siga/interrompa projetos individuais, além de desenvolver uma nova estratégia de produtos para o negócio, completado pela decisão de alocação estratégica dos recursos disponíveis (COOPER et al., 1998).

Nesse contexto, Cheng (2000) estabelece três objetivos para a gestão de portfolio: alinhamento estratégico dos projetos de desenvolvimento com a estratégia do negócio (CLARK; WHEELWRIGHT, 1993; COOPER et al., 1998), maximização do valor do portfolio levando em consideração os recursos disponíveis (COOPER et al., 1998) e o balanceamento entre projetos a partir de critérios diversos (COOPER et al., 1997a). É importante destacar que existem diferenças no desenvolvimento do novo produto no que tange a abrangência e profundidade de mudanças, tanto para o produto, quanto para o processo de produção. Nesse sentido, Clark e Wheelwright (1993) classificam os projetos conforme mostrado na Figura 3.

A Figura 3 está associada ao lado esquerdo da Figura 2. Esta parte é relacionada à escolha dos projetos, uma vez que é necessário estabelecer quais tipos de projetos devem ser desenvolvidos pois, dependendo da complexidade do projeto do produto, mais recursos para seu desenvolvimento são necessários, incluindo a gestão do seu desenvolvimento (lado direito da Figura 2). Nesse sentido, vale a pena destacar os projetos do tipo "plataforma" e os "derivativos" mostrados na Figura 3. Os projetos derivativos, híbridos, ou de melhorias são também denominados de projetos de sustentação, e que podem variar desde versões de custo reduzido de um produto existente até projetos de melhoria de um processo de produção existente. Como sugerido pelo posicionamento desse tipo de projeto na Figura 3, tais projetos incluem mudanças incrementais no produto com pouca ou nenhuma alteração de processo, mudanças incrementais de processo com pouca ou nenhuma alteração do produto, ou produtos que envolvem (pouca) mudança de projeto e de processo. Esses projetos geralmente requerem muito menos recursos do que projetos que trazem avanços significativos, pois eles simplesmente melhoram os produtos ou os processos existentes por meio de uma extensão na sua aplicação.

\section{A gestão de portfolio compreende o gerenciamento estratégicos da organização de forma compatível com os recursos disponíveis para sua realização.}

Os projetos plataforma representando um novo "sistema" de solução para os clientes, envolvem mudanças significativas tanto para o processo de fabricação quanto para o produto, ou para ambos. Os projetos plataforma fornecem uma base para uma família de produtos ou processos, cuja evolução colocará esses produtos e processos em outro patamar por muitos anos, e requerem significativamente mais recursos comparados aos projetos derivativos ou incrementais. Quando esses projetos são cuidadosamente planejados e executados, eles fornecem uma base significativa em volume e uma melhoria fundamental nos custos, qualidade, e desempenho comparativamente com a geração anterior. Por essa razão, eles são freqüentemente referidos como "próxima geração".

Além desses dois tipos (plataforma e derivativos), existem os projetos de ruptura ou radicais que podem estabelecer um novo núcleo de produtos e processos. Eles podem criar uma nova categoria de produtos nos negócios da organização ou encabeçar a entrada da organização em um novo negócio. A maior parte do foco de tais tipos de projetos é no produto, pois, freqüentemente representa uma nova aplicação ou função e depende da atração e satisfação de novos clientes para seu sucesso. Os projetos de parceria representam um modo diferenciado de condução de projeto, e podem envolver extensas alterações de produto ou processo de produção. $\mathrm{Na}$ verdade, qualquer projeto pode ser conduzido utilizando-se 
de parceria, ou seja, a organização pode formar uma aliança ou criar uma parceria com outra instituição para conduzir pesquisa ou desenvolvimento avançado, para desenvolver um novo conceito de produto, ou simplesmente ampliar uma linha de produtos. Ao invés de se utilizar somente dos recursos próprios da organização, a empresa parceira freqüentemente fornece recursos únicos e/ou significativos (às vezes todos os seus recursos disponíveis), podendo, inclusive, gerenciar a execução do projeto.

Os projetos de desenvolvimento devem ser escolhidos de acordo com as estratégias de desenvolvimento de novos produtos da organização e pela disponibilidade de recursos que a empresa possui (MARSON, 2003). Assim, é importante classificar o tipo de projeto (por exemplo, plataforma ou derivativo) e analisar, estrategicamente, o quanto o desenvolvimento proposto é novo para a empresa (Figura 4).
Isso pode significar a necessidade de busca de competência necessária para o desenvolvimento (como no caso de um projeto de parceria) podendo, como citado anteriormente, implicar em um projeto do tipo plataforma, derivativo ou de ruptura.

As diferenças entre os desenvolvimentos mostrados na Figura 4 implicam em uma maior ou menor competência da organização em desenvolvê-los e também no consumo de recursos para a(s) equipe(s) de desenvolvimento. A empresa precisa, portanto, definir sua estratégia de desenvolvimento de novos produtos a partir da estratégia de negócio da organização, tendo a necessidade de definir qual o nicho de mercado que a plataforma pretende atingir (MEYER, 1997). Em suma, a prática de gestão de portfolio envolve a decisão sobre quais projetos devem ser acrescentados à carteira ativa de projetos de uma empresa, definição do tipo de projeto e

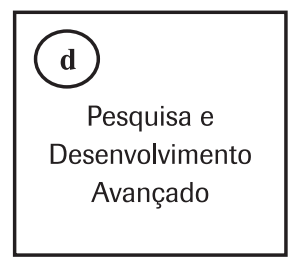
Extensão das Mudanças
no Processo
Extensão das Mudanças no Produto

Novo núcleo Próxima gera- Adições à famí- Derivativos de produtos ção de produtos lia de produtos e melhorias

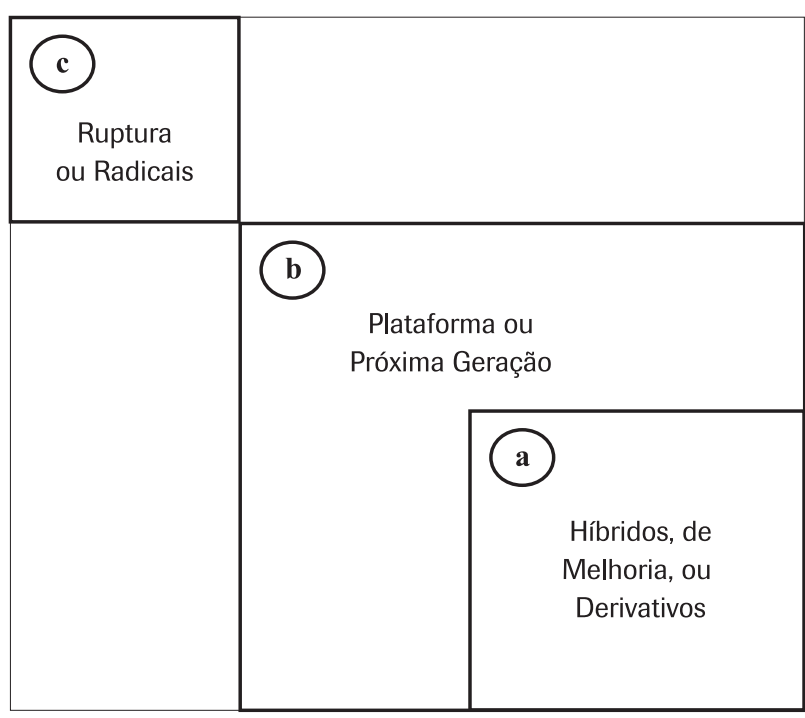

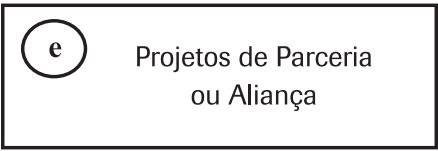

Figura 3: Tipos de Projetos de Desenvolvimento.

Fonte: Clark e Wheelwright, 1993 
seus objetivos, e prazos e recursos necessários para executálos. Uma vez feita a análise do conjunto dos projetos a ser desenvolvido, a atenção é voltada para o desenvolvimento de cada projeto individualmente (lado direito da Figura 2). Afim de que isso ocorra, geralmente as empresas utilizam processos estruturados de desenvolvimento. Em geral, este processo de desenvolvimento de um novo produto compreende a seguinte seqüência: geração de idéia, investigação, desenvolvimento do projeto, produção, e lançamento. A literatura apresenta vários destes processos para desenvolver um novo produto, dentre eles o funil de desenvolvimento (CLARK e WHEELWRIGHT, 1993) e o stage-gate (COOPER, 1993). Dentre outras proposições mais recentes está o modelo de referência de Rozenfeld et al. (2006) que, na verdade, pode ser considerado como uma variação das propostas anteriores.

\subsection{Visão Geral sobre os Processos de Desenvolvimento de Novos Produtos}

O funil de desenvolvimento (Development Funnel) trata de modo integrado das atividades básicas do desenvolvimento de produto (FONSECA; ANDERY, 2001), permitindo gerar e revisar alternativas, observar a seqüência de decisões críticas e avaliar a natureza da tomada de decisões (CLARK; WHEELWRIGHT, 1993). A forma de funil ocorre justamente porque existe um processo de tomada de decisões que reduz o número de opções disponíveis na atividade de projeto ao longo do tempo (FONSECA; ANDERY, 2001). Este processo de desenvolvimento consiste de quatro estágios compreendidos por (CLARK; WHEELWRIGHT, 1993): conceito e desenvolvimento, planejamento do pro- duto, engenharia do processo e produto, e produção piloto e aumento de produção ( $r a m p-u p)$. As idéias estão localizadas na boca do funil e, na medida em que são selecionadas, avançam para o desenvolvimento, após a tomada de decisão que devem ser desenvolvidas. Na realidade, o surgimento das idéias e avanço em direção ao (funil de) desenvolvimento são geralmente impulsionados pelo mercado e pela tecnologia. Do lado do mercado, as idéias são puxadas pelas demandas de atendimento a um determinado segmento de mercado ou pela necessidade gerada pelos competidores, enquanto a tecnologia também pode impulsionar as idéias em função da sua disponibilidade e viabilidade sob o ponto de vista comercial. Estas idéias tornam-se projetos para serem desenvolvidos e vão então avançando na medida em que se executam atividades relacionadas ao desenvolvimento do novo produto, considerando os dados técnicos e mercadológicos, a partir das três dimensões de custo do produto, tempo para desenvolver o produto e desempenho do produto (ROSENAU apud PHILLIPS et al., 1999). Para exemplificar, dentre as empresas que implantaram o funil de desenvolvimento estão a Natura (NASCIMENTO; MARX, 2001) e a Sandvik (SANTOS; PASCHOARELLI, 1998).

De forma análoga ao processo do funil, Duncan (1996) apresenta quatro estágios similares porém acrescentando um estágio "zero" chamado de "exploração". A existência desse estágio também é relevante, em razão da atenção que deve ser dada aos estágios iniciais de pré-desenvolvimento, em função de que a complexidade envolvida no desenvolvimento de um novo produto tende a aumentar na medida em que o desenvolvimento avança (GRIFFIN, 1997). Assim, concentrar esforços nas fases iniciais, sem dúvida possibilita

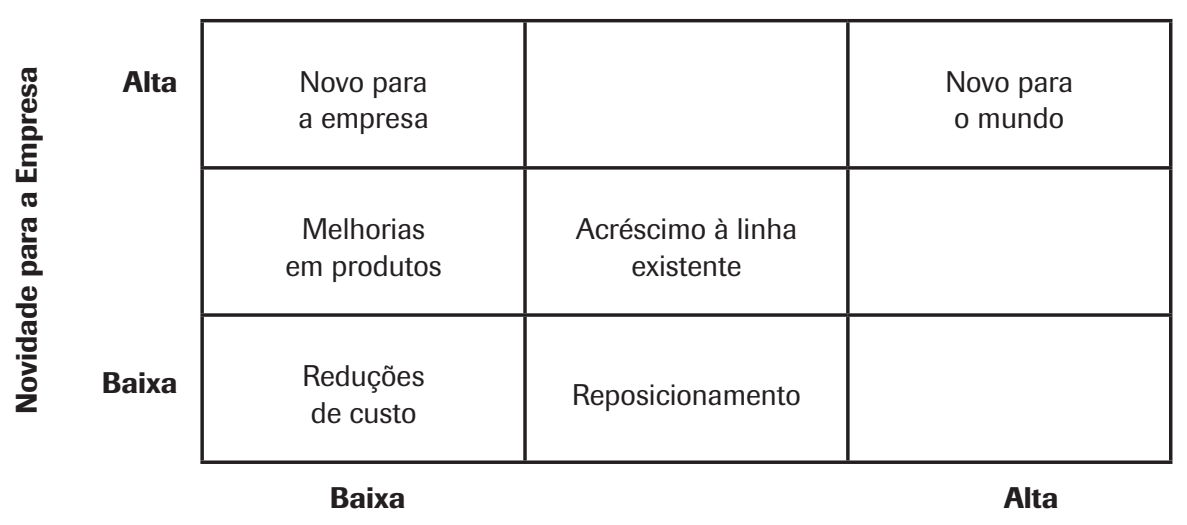

Novidade para o Mercado

Figura 4: Classificação dos Projetos

Fonte: Griffin e Page, 1996. 
alcançar um desenvolvimento mais eficaz (atingir o que é esperado, ou seja, alcançar o sucesso técnico e comercial) e mais eficientemente (atingir os resultados esperados da forma mais otimizada possível).

Nesse sentido, a proposta colocada por Cooper (1993) apresenta-se como uma abordagem de processo útil e interessante. $\mathrm{O}$ autor apresenta uma estrutura denominada genericamente de "stage-gate", como sendo uma abordagem que divide o processo de desenvolvimento em estágios discretos e identificáveis, tipicamente na quantidade de 4,5 ou 6 estágios. Cada um dos estágios é desenvolvido para obter as informações para que o projeto possa progredir para o
- Validação e teste: testes em laboratório, na própria planta industrial ou no mercado para verificar e validar o novo produto proposto e sua produção.

- Produção e lançamento: início da produção, esforços direcionados de marketing e de comercialização do produto.

As melhores práticas para desenvolvimento de um novo produto podem ser apoiadas pela implementação da abordagem do stage-gate (GRIFFIN, 1997), como no caso das seguintes empresas que introduziram o stage-gate e suas variantes (PHILLIPS et al., 1999): Bombardier Aerospace Group, Kodak, General Electric, Lucas Industries plc, Rolls-Royce plc e Motorola. Os autores fazem uma comparação entre os processos de stage-gate das organizações citadas a partir da proposição de um stagegate genérico com quatro estágios, concluindo que, apesar de serem diferenciados em alguns detalhes, os processos das empresas seguem a proposição do stage-gate genérico. Embora o conteúdo do trabalho não permita uma conclusão mais

estágio seguinte, antes passando por um ponto de decisão denominado de gate, que precede cada estágio. Os gates servem como pontos de verificação de controle da qualidade, atuando como pontos de decisão se o projeto continua ou deve ser abortado (COOPER, 1993); os gates são predefinidos e especificam um conjunto de atividades a serem cumpridas para o estágio em análise, utilizando-se de uma série de critérios ou outputs. Geralmente, a avaliação nos gates é conduzida por um gerente sênior ou por um comitê de projetos formado por um grupo de gerentes sêniores da organização. Os estágios de desenvolvimento do stage-gate são os seguintes (COOPER, 1993):

- Investigação preliminar: um rápido estudo inicial e verificação do escopo do projeto.

- Investigação detalhada: um estudo em mais detalhes, podendo, geralmente, resultar na elaboração de um plano de negócios, incluindo a definição e a justificativa do projeto e também um plano para o seu desenvolvimento.

- Desenvolvimento: desenvolver o novo produto propriamente dito, compreendendo a definição das suas especificações, do processo de produção, construção dos protótipos, bem como especificação dos meios de controle da qualidade (para o produto e do projeto), além da determinação dos custos. incisiva, os autores (PHILLIPS et al., 1999) afirmam que as empresas que trabalham com uma estrutura matricial multi-funcional tendem a ser mais próximas da estrutura genérica, que considera quatro estágios de desenvolvimento, enquanto que as organizações com uma estrutura de desenvolvimento mais funcional tendem a adotar uma quantidade maior de estágios com revisões formais periódicas dentro dos estágios. Outras variantes dessas propostas de processos de desenvolvimento de produtos incluem os trabalhos de Rahman (1995), Duncan (1996) Gunasekaran et al. (1998) e Peters et al. (1999).

Finalmente, um trabalho recente importante para o desenvolvimento de novos produtos é o de Rozenfeld et al.(2006). Os autores apresentam um modelo detalhado para o desenvolvimento de novos produtos, baseado em três macroprocessos (pré-desenvolvimento, desenvolvimento, e pós-desenvolvimento) e respectivos estágios, atividades e ferramentas utilizadas nesse processo. A Figura 5 ilustra esse processo. O processo proposto pelos autores é complexo, bem detalhado e cobre uma importante lacuna para a área de desenvolvimento de novos produtos no Brasil. Não cabe, portanto, fazer o seu detalhamento neste trabalho. Esta proposta é importante para o presente estudo pois trás uma referência teórica mais atual no sentido de discutir alguns pontos no estudo empírico apresentado mais à frente. 


\section{MÉTODOS E TÉCNICAS DE PESQUISA}

Primeiramente cabe destacar que a literatura atual aborda o tema (gestão de portfolio) sob diferentes vertentes, sejam estas teóricas ou empíricas. No entanto, os trabalhos empíricos de implantação são relativamente escassos no país, apesar da existência de publicações recentes relevantes, como os trabalhos de Moraes e Laurindo (2003) e Rabechini Júnior et al. (2005), embora com enfoques diferentes do presente trabalho. Nesse sentido, o presente trabalho pretende trazer uma contribuição no aspecto empírico. A questão de pesquisa é a associada a como ocorre a implementação da gestão de portfolio, sua relação com o processo de desenvolvimento de novos produtos, revisão nos gates (tipo destes e respectiva documentação utilizada), além de identificar a relação entre as decisões (de implementação) tomadas com a literatura.

Nesse contexto, o presente trabalho utiliza como abordagem metodológica o estudo de caso, a partir da literatura, principalmente com base nos trabalhos de Yin (1994) e Voss et al. (2002). A escolha dessa abordagem pode ser justificada em função de que o pesquisador praticamente não tem controle sobre os eventos (sua participação ocorreu como observador passivo), o contexto é relevante (pois trata-se de uma implementação e tem-se então a oportunidade de relatar e analisar como foi conduzida a partir do estabelecido na literatura), e o tema é contemporâneo (pois nota-se uma discussão mais intensa pela literatura ao longo da última década).
A seleção da unidade de análise (empresa) foi intencional, pois tomou-se conhecimento, por intermédio de outro projeto de pesquisa, que esta implementaria a gestão de portfolio para desenvolvimento de novos produtos. A empresa, de médio porte (com aproximadamente 350 funcionários e cerca de R $\$ 100$ milhões de faturamento anual, tomando-se o critério do INMETRO para classificação do porte da empresa) possui uma unidade industrial, projetando e fabricando produtos direcionados para vários negócios no setor de embalagens, proporcionando, assim, um cenário relevante para o estudo. A empresa conta ainda com um conjunto de produtos na carteira de desenvolvimento relativamente grande (da ordem de duas dezenas) e teve recente alteração de sua estratégia, pois pretendia tornar-se a líder na América Latina (na ocasião do estudo detinha aproximadamente um terço do mercado latinoamericano). Estes aspectos, associado ao acesso facilitado aos dados, resultaram, portanto, em uma oportunidade quase que única para a condução da pesquisa, justificando, portanto, a escolha da unidade de análise.

Além dos fatores anteriormente apontados (escolha da abordagem metodológica e seleção da unidade de análise), os dados são de natureza qualitativa, o que também direciona a abordagem metodológica para a condução de um estudo de caso, devido ao caráter usual da natureza dos dados nesse tipo de abordagem. Diversas fontes de evidência foram utilizadas, destacando-se o acompanhamento das reuniões de portfolio com a alta direção e a análise documental a partir do acesso a documentos tais como: plano para implementação

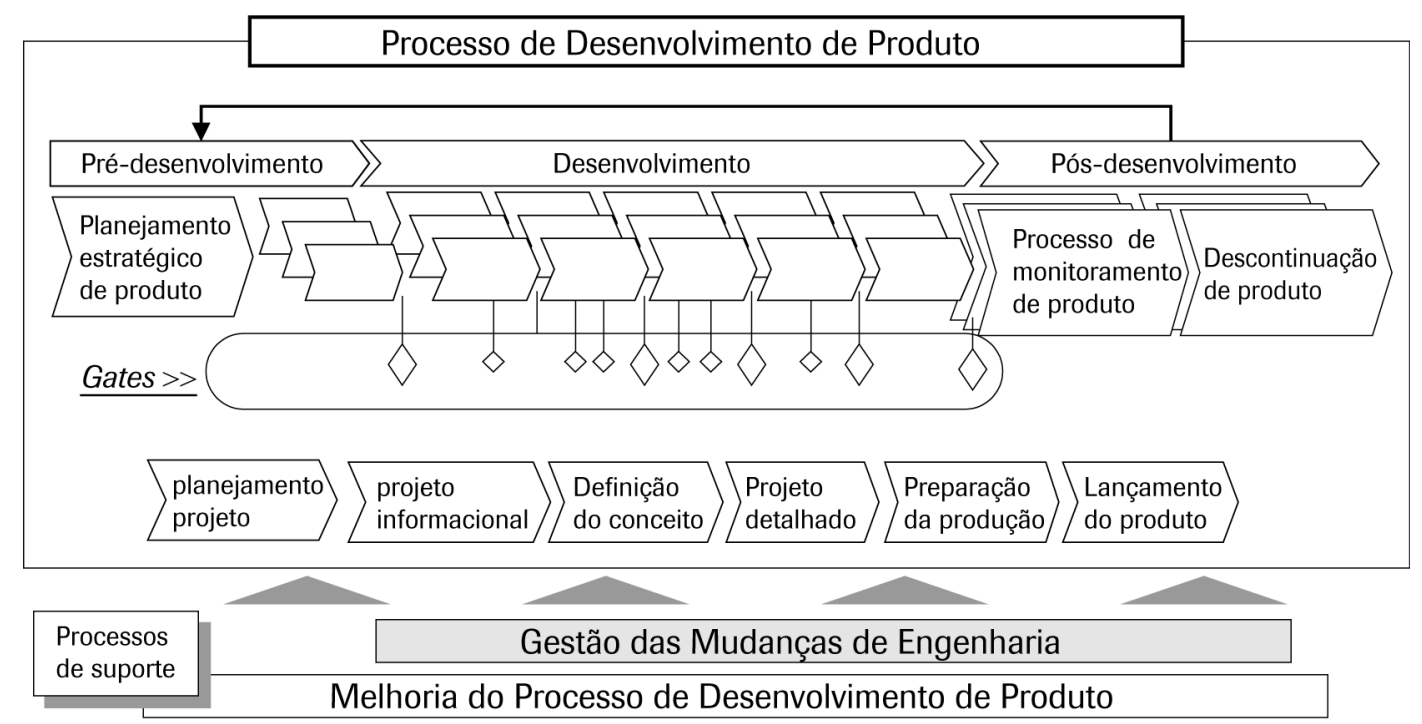

Figura 5: Modelo de referência de Rozenfeld et al. (2006). 
do gerenciamento de portfolio, manual de gestão de projetos da empresa, planilha de portfolio de novos produtos, registros individuais de projetos de novos produtos, relatórios de gestão e outros documentos (e.g.: atas, memorandos, etc.). Além dessas fontes, algumas entrevistas espontâneas (não estruturadas) foram feitas com a alta gerência da empresa (principalmente com o gerente de $\mathrm{P} \& \mathrm{D}$ e com o coordenador geral de projetos), e com alguns membros das equipes de desenvolvimento de novos produtos (visando, principalmente, a obtenção de dados e informações sobre as revisões nos gates).

Os dados de caráter qualitativo foram interpretados a partir dos meios de registros citados, principalmente com base nas anotações em um diário de pesquisa. Essa análise seguiu uma lógica indutiva, ou seja, pelo estabelecimento de uma cadeia de raciocínio partindo-se de dados particulares para tentar-se chegar a fatos gerais, conforme definido por Andrade (2002). Também foi usada a técnica de triangulação visando confrontar as fontes utilizadas para identificar convergência ou não dos seus conteúdos. Finalmente, visando a confiabilidade e a qualidade do trabalho, os seguintes tipos de validade foram considerados: a validade interna foi observada para constatar se a interpretação dos dados e as conclusões obtidas eram decorrentes das fontes de evidência; a validade descritiva para assegurar que o relato advindo das fontes representava a situação pesquisada; e a validade interpretativa, visando garantir que a interpretação era decorrente do que estava sendo investigado. A partir da construção de uma narrativa, decorrente das fontes de evidência adotadas e da consideração dos tipos de validade anteriormente apontados, o caso foi construído a posteriori, cujo conteúdo é detalhado na seqüência.

\section{GESTÃO DE PORTFOLIO - UM CASO DE IMPLEMENTAÇÃO}

O contexto deste trabalho envolve uma reestruturação no sistema de desenvolvimento de novos produtos de uma empresa. Uma das iniciativas em curso era a implantação do gerenciamento do portfolio de desenvolvimento de novos produtos e a introdução de um processo estruturado para desenvolvê-los. A Figura 6 mostra a inter-relação entre essas iniciativas.

A parte esquerda da Figura 6 ilustra a gestão de portfolio, consistindo de três "listas": banco de idéias a serem desenvolvidas (eventualmente tornar-se-ão projetos), uma lista de projetos "em espera" (aguardando recursos para serem desenvolvidos, conforme a prioridade estratégica), e uma relação de projetos "ativos" (sendo desenvolvidos simultaneamente). Entretanto, antes de uma idéia tornar-se um projeto, pode haver a necessidade de uma investigação mais profunda. Nesse caso, a idéia tornar-se-ia um projeto funcional a fim de que fosse estudada sua viabilidade tecnológica, tanto como produto como para o processo de produção para obtê-lo. A parte central da figura ilustra um projeto individual (denominado de XY), que faz parte da carteira de desenvolvimento (está na carteira de projetos "ativos") e que teve recursos alocados para seu desenvolvimento, e que, portanto, estará entrando no processo de desenvolvimento que compreende os estágios e gates mostrados na parte direita da figura.

Como primeiros passos, primeiramente, deveria ser feito um mapeamento da carteira de desenvolvimento de produtos existente na ocasião, bem como realizar uma comparação desse portfolio com a capacidade instalada da empresa

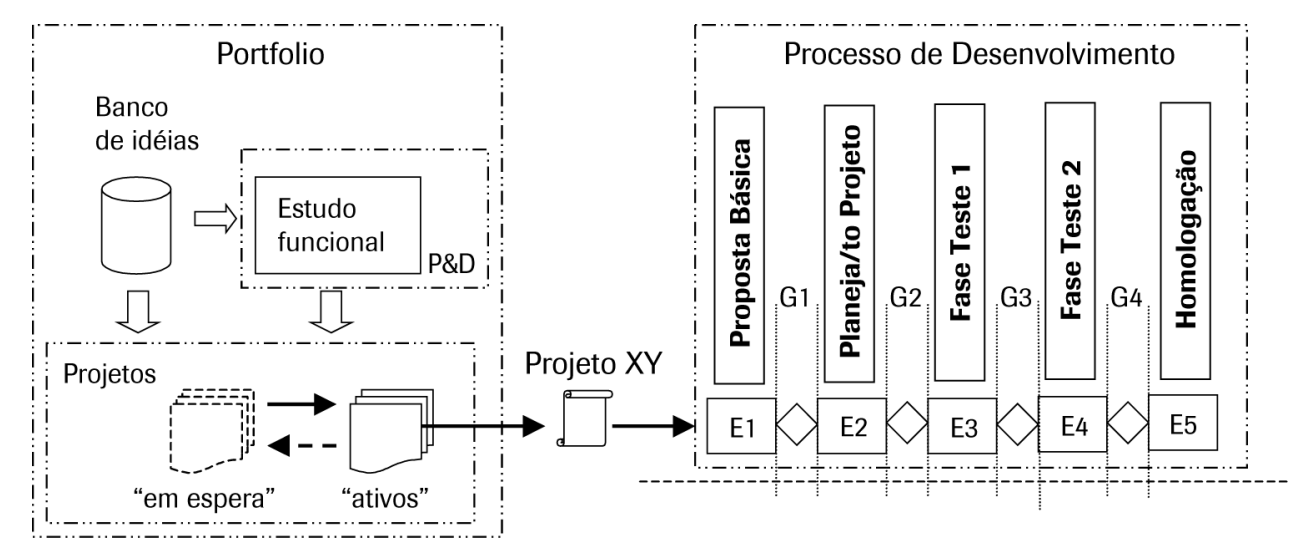

Figura 6: Relação entre o Portfolio e o Processo de Desenvolvimento de Produtos. 
para desenvolver novos produtos. Finalmente, deveriam ser estabelecidos critérios para que um projeto (ou uma idéia) pudesse adentrar na carteira de desenvolvimento. Esses passos são detalhados a seguir. É importante destacar que esses passos foram levantados empiricamente com base nas fontes de dados disponíveis e, não necessariamente, estavam completamente estabelecidos.

\subsection{Implantação do Portfolio de Desenvolvimento}

Com relação à gestão dos projetos de novos produtos em desenvolvimento, era latente a necessidade da empresa de definir um processo que possibilitasse compatibilizar a sua estratégia de negócios (recentemente revista) com a decisão de qual deveria ser o conjunto de projetos de produtos que deveria vigorar. Nesse sentido, os passos a seguir foram estabelecidos.

\subsubsection{Definição da estrutura organizacional e de responsabilidades}

Primeiramente, foi estabelecido um comitê de projeto, definido como a instância máxima de gestão dos projetos na empresa, sendo formado por gerentes funcionais (marketing, $\mathrm{P} \& \mathrm{D}$, comercial, qualidade e produção) e pelo diretor geral da empresa. Esse comitê passaria a ser responsável pela gestão de desenvolvimento de produtos, alterando a responsabilidade que era funcional, da área de P\&D, ampliando a responsabilidade para a empresa como um todo, provocando uma mudança na estrutura organizacional da gestão de projetos passando a ser matricial (ver PMI, 2004). O comitê é quem analisaria todas às idéias propostas na empresa, realizando as reuniões de portfolio, avaliando os projetos nos gates, definindo quem seria o gerente de projetos, e aprovando a equipe multifuncional. A estrutura organizacional para gestão de projetos na empresa foi estabelecida em uma organização matricial como ilustrada na Figura 7, tendo como base os princípios do PMBoK do PMI (2000).

A estrutura mostrada na Figura 7 baseia-se na formação de equipes temporárias, com pessoas de todas as áreas envolvidas com o desenvolvimento de novos produtos. Assim, esta estrutura permite conduzir vários projetos simultaneamente. Um profissional da empresa é designado como gerente do projeto, responsável por apresentar e explicar os planos de projeto para o comitê de projeto, além de indicar a equipe do projeto e as responsabilidades das pessoas que fazem parte dessa equipe. Esse profissional pode vir de qualquer área funcional da organização e pode assumir uma ou mais gerências de projetos de desenvolvimento. É importante mencionar que existe um limite de participação, tanto dos gerentes de projeto, como dos membros das equipes em termos de quantidade de projetos. Para a empresa estudada, após a estruturação do processo de desenvolvimento de novos produtos, a quantidade típica era a participação de 1 a 3 projetos (1,5 em média em um grupo de 39 pessoas, sendo a maior parte - 59\% - participando em somente um projeto). Anteriormente, os profissionais da empresa chegavam a trabalhar em até 6 projetos simultaneamente, o que não pode ser considerado como adequado, tomando-se como base a Figura 8 (CLARK; WHEELWRIGHT, 1993).

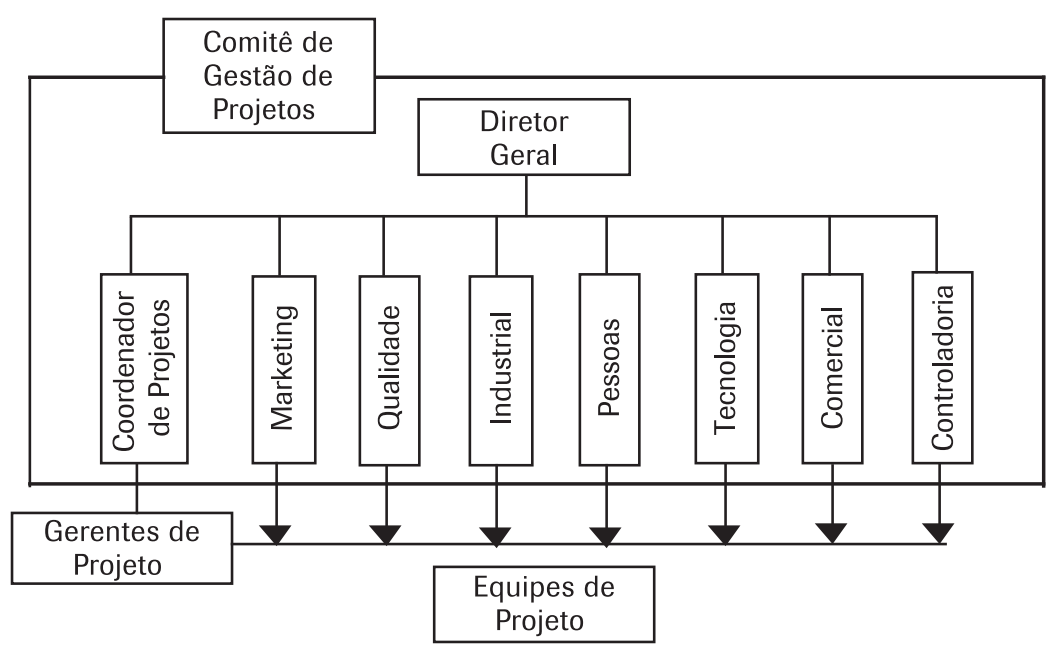

Figura 7: Estrutura Organizacional. 
O arranjo estrutural da empresa, em relação à organização do grupo de desenvolvimento, deve ser definido a partir da importância e função da natureza do trabalho de desenvolvimento de produto (CLARK; WHEELWRIGHT, 1993; PMI, 2000). Os arranjos típicos são do tipo funcional, matricial e força tarefa. A empresa adotou o tipo matricial leve (ou "peso leve", que significa a autoridade do gerente do projeto sobre os membros da equipe, que também respondem a sua respectiva gerência funcional).

\subsubsection{Confecção de uma lista de projetos subdivididos por negócios}

Os projetos de novos produtos foram classificados conforme o tipo (plataforma ou derivativos) e também de acordo com sua tipologia em função de relevância em termos estratégicos (aperfeiçoado no passo seguinte). Essa lista, na verdade, gerou três outras listas (Figura 6): projetos ativos, aqueles que estavam em desenvolvimento; projetos em espera, aqueles que aguardavam recursos em termos de capacidade de desenvolvimento; e um banco de idéias, que eram inputs internos ou externos (por exemplo advindos do mercado) sobre possibilidades de desenvolvimento, ou seja, idéias que poderiam gerar produtos com potencial comercial.

\section{a gestão dos projetos de desenvolvimento de novos produtos era latente a necessidade da empresa de} definir um processo que possibilitasse compatibilizar a sua estratégia de negócios (recentemente revista) com a decisão de qual era o conjunto de projetos de produtos

\section{que deveria estar em vigor.}

\subsubsection{Derivar a estratégia de desenvolvimento de novos produtos a partir da estratégia de negócios (alinhamento entre as estratégias e o portfolio)}

Nesse passo, foi necessário obter dados de faturamento e lucratividade dos produtos atuais nos últimos três anos. Além disso, foi também necessário elaborar projeções de faturamento para os três anos sucessivos. Assim, poder-se-ia analisar cada projeto dentro das perspectivas históricas de sua plataforma e pela previsão futura. Essa análise também possibilitaria definir uma data prevista para início e término de cada projeto a partir da previsão de faturamento no período. Finalmente, deveria ser estabelecida uma forma de orçar os projetos individuais a fim de verificar seu impacto no orçamento global.

\subsubsection{Desenvolver uma planilha representando o portfolio de produtos}

Para compor o portfolio, foram definidos critérios de natureza qualitativa e quantitativa visando estabelecer um mapa da carteira de novos produtos para a tomada de decisão de quais projetos deveriam ser priorizados. Dados gerais do projeto do novo produto foram colocados primeiramente, tais como: o título do projeto, seu escopo, o código do produto e a área de negócios a que pertencia. A seguir, os projetos foram classificados como derivativos ou plataforma, segundo Clark e Wheewright (1993), e os seguintes critérios adicionais para avaliação foram adotados: impacto estratégico (alto, médio, baixo); origem do projeto (da própria empresa ou dos clientes); grau de inovação (local, fast follower ou follower, conforme GRIFFIN; PAGE, 1996); dificuldade tecnológica - de produto ou de processo de produção (alta, média, baixa), objetivo em termos de grau de novidade para o mercado (novo, substituição, melhoria, ou redução de custo), segundo Griffin e Page (1996); previsão de vendas (volume médio no primeiro ano, preço-alvo, custo-alvo) e importância, indicando se o produto era um produto "especial" (a empresa denominava de "especialidade") ou um produto do tipo commodity (ambos classificados em uma escala Lickert de 5 pontos, sendo 1 - "é um pouco importante" e 5 "é muito importante"). Assim, com base nesses critérios, a prioridade poderia ser definida. Uma ilustração dessa planilha é mostrada na Figura 9. Devido a questões de confidencialidade, os dados reais não puderam ser mostrados.

\subsubsection{Aperfeiçoar o processo de desenvolvimento da empresa definindo os gates}

A empresa estudada decidiu pelo uso do modelo de stagegate, proposto por Cooper (1993), como seu processo de desenvolvimento de novos produtos. O processo de desenvolvimento foi composto por cinco estágios denominados: Proposta Básica, Planejamento do Projeto, Desenvolvimento Fase Teste 1, Desenvolvimento - Fase Teste 2 e Homologação, como ilustrado na Figura 10. Os estágios definem o conjunto de atividades a serem realizadas, enquanto os gates consistem nos pontos de decisão para verificar se as atividades previstas são cumpridas. Os gates consideram três tipos básicos de decisão: "aprovado" (segue para o estágio seguinte), "necessita de mais informações" (permanece no estágio atual), e "reprovado" (o projeto é arquivado suspenso ou abortado), demonstrando ser um gate de 
primeira geração, conforme a classificação de Rozenfeld et al. (2006).

Os estágios mostrados na Figura 10 compreendem as seguintes atividades:

Proposta básica: envolve as informações gerais quanto ao objetivo do projeto, especificações iniciais de desempenho requerido do produto e negócio alvo. Um gerente de projeto é designado para esse projeto nessa fase, o qual indica a equipe. Também são descritos os recursos e informações para os dados de entrada, são discriminados os documentos de referência para a proposta, bem como outros recursos (por exemplo, informações preliminares de mercado potencial, qualidades exigidas pelos clientes potenciais, etc.). Esse estágio passa pelo gate seguinte que analisa se os critérios foram cumpridos ou se há necessidade de mais informações para prosseguir com o projeto.

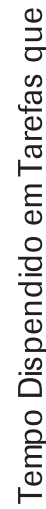

음

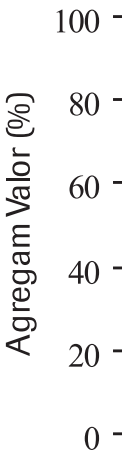

Número de Projetos de Desenvolvimento Designados

Simultaneamente por Engenheiro

Figura 8: Dimensionamento da Capacidade Instalada.

Fonte: Clark e Wheelwright, 1993.

\begin{tabular}{|c|c|c|c|c|c|c|c|c|c|}
\hline Tipo & Escopo & Produto & \multicolumn{5}{|c|}{ Classificação } & & 12345 \\
\hline 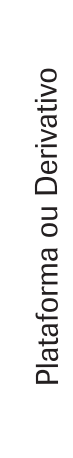 & 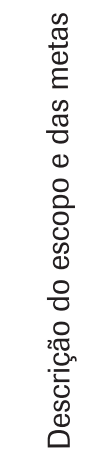 & 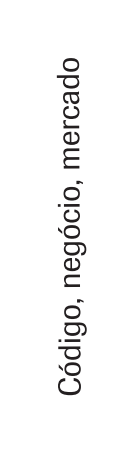 & 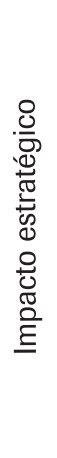 & 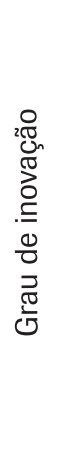 & 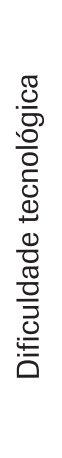 & $\begin{array}{l}\frac{0}{0} \\
\frac{0}{0} \\
\frac{0}{2} \\
0 \\
0 \\
0 \\
0 \\
.00 \\
\frac{0}{0}\end{array}$ & 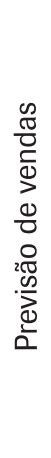 & 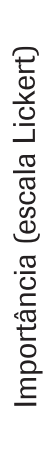 & 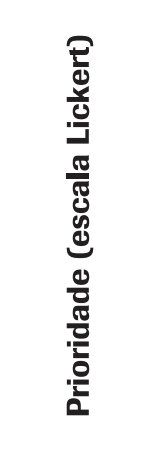 \\
\hline
\end{tabular}

Figura 9: llustração dos Critérios Usados na Planilha. 
Planejamento do projeto: envolve um maior detalhamento das informações gerais, tais como a elaboração do cronograma do projeto, a aprovação ou alteração da composição da equipe de projeto, a obtenção e discussão mais detalhada dos dados de entrada, a descrição do produto e dos requisitos básicos da qualidade, e a análise mercadológica e análise preliminar de viabilidade econômico-financeira. Também são discriminados neste estágio os documentos de referência, bem como é confirmada equipe para a condução subseqüente do projeto e reconfirmação dos dados de entrada.

dos dos dados de entrada, bem como é feita uma verificação de cumprimento do cronograma.

Fase teste 2: este estágio compreende o aumento gradativo na escala de produção (scale up) para a alternativa final escolhida na fase anterior. Nesse caso, já devem estar definidos os aspectos legais quanto ao produto (como, por exemplo, restrições de embalagens em contato com alimentos). Em termos documentais, este estágio considera a descrição final do produto, a definição final dos indicadores técnicos, industriais e financeiros, bem como a análise final da relação entre os dados de entrada e os de saída. Também são discriminados os documentos de referência, bem como é feita uma nova confirmação dos dados de entrada, além de ser verificado o cumprimento do cronograma inicial.

Homologação: compreende a disponibilização de um data sheet (conjunto de especificações técnicas registradas em um documento) do produto, disponibilização das especificações de processo e dos planos de controle, bem como dos argumentos de venda a serem utilizados para a co-

Fase teste 1: este estágio compreende o desenvolvimento do processo de produção e dos primeiros protótipos (denominado "amostras" na empresa estudada). A partir de vários testes de produção, é feita a escolha da solução mais adequada, tendo em vista as alternativas dos testes conduzidos nos experimentos planejados. Também são realizados os primeiros testes para clientes específicos (geralmente esses clientes são parceiros mais próximos, considerados como mercado de teste). Em termos documentais, este estágio considera uma possível revisão no cronograma, na descrição do produto, na descrição dos indicadores técnicos, industriais e financeiros, bem como uma análise mais aprofundada da relação entre os dados de entrada e os de saída. Além disso, são discriminados os documentos de referência, confirma- mercialização do produto. Também deve ser realizada uma revisão nos sistemas de informação da empresa (cadastramento das informações do produto), bem como o produto deve estar aprovado em órgão específico, como, por exemplo, para o caso de contato da embalagem com alimentos.

Também devem ser estabelecidos os critérios para os gates e quem tomaria as decisões, no caso o comitê de projetos, bem como com que periodicidade seriam verificados os projetos de novos produtos (follow-up), ou seja, as datas de reuniões de acompanhamento de cada projeto individualmente, mensal ou bimestralmente. Outro aspecto importante é com relação à documentação usada nos gates. O Quadro 1 apresenta uma síntese do conteúdo dos documentos principais utilizados nos gates.

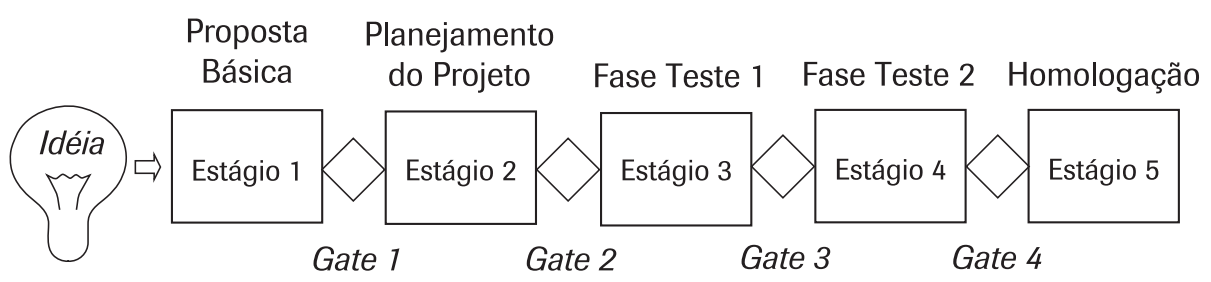

Figura 10: Processo de Desenvolvimento da Empresa. 


\section{1.6 Estabelecer reuniões de revisão de portfolio}

O objetivo das reuniões de portfolio é a realização de ajustes no conjunto de projetos, decidindo as possíveis alterações nesse conjunto, ou seja, projetos que poderiam entrar no portfolio, em função da conclusão de outro(s) ou projetos que deveriam ser interrompidos (suspensos ou abortados) em função de alterações de mercado ou outros fatores nos quais a empresa tem ou não controle. Os projetos então poderiam passar da lista de projetos "em espera" para "ativos" e vice-versa. Além disso, poderiam ser definidos projetos que estavam no banco de idéias, para serem desenvolvidos. A periodicidade dessas reuniões variou, sendo realizadas a cada três ou seis meses.

Até a finalização da coleta de dados, o sistema de gestão de portfolio encontrava-se em vigência e os resultados indicavam uma melhoria significativa na gestão do conjunto dos projetos, embora os resultados de desempenho não tenham sido quantificados. Houve, inclusive, um aperfeiçoamento, considerando uma subdivisão de cada lista do portfolio (ativos, em espera, e banco de idéias, mostrados na Figura 6) em: desenvolvimento de produto, desenvolvimento de aplicação e desenvolvimento de conceito. O desenvolvimento de produto refere-se ao desenvolvimento de projetos dentro de uma estrutura de trabalho matricial envolvendo as áreas funcionais necessárias (comercial, produção, $\mathrm{P} \& \mathrm{D}$, etc.). Por outro lado, o desenvolvimento de conceito envolve uma atividade mais tradicional da área de $P \& D$, ou seja, uma atividade tipicamente funcional onde deveriam ser estudadas as alternativas de conceito para um mesmo produto. $\mathrm{O}$ desenvolvimento de aplicação é mais simplificado pois, geralmente, envolve o desenvolvimento de uma nova aplicação para um produto tradicional já comercializado pela empresa (por exemplo um projeto derivativo com alteração somente em - poucas - condições de manufatura). Nesse último caso, o projeto entra em um processo mais rápido denominado fast track, caso o lançamento desse produto tivesse certa urgência, seja para preencher uma lacuna existente no mercado ou para fazer frente à concorrência. Assim, cada projeto novo passaria por uma análise ilustrada na Figura 11.

A Figura 11 indica que, para desenvolver uma nova idéia, é necessário que seja investigado se a empresa tem competência suficiente para tal. No caso de não ser um novo produto, mas uma nova aplicação, isto é, a adoção de uma tecnologia existente para um outro emprego (ou seja, o uso de um produto existente para um outro negócio), é preciso que esta nova aplicação seja desenvolvida, sem a necessidade de estabelecer um projeto matricial, mas sim um fast-track, tendo como responsável um engenheiro de desenvolvimento. Se não houver uma nova tecnologia envolvida, o projeto inicia o desenvolvimento do novo produto em uma estrutura de desenvolvimento tipicamente matricial. Em último caso, se for uma nova tecnologia, é então necessário aprofundar o estudo de forma a desenvolvê-la, caracterizando-se como um projeto tipicamente funcional da área de P\&D. Assim, tem-se como resultado uma análise mais depurada das implicações, em termos de desenvolvimento de novo produto e respectivos recursos, do que será necessário para desenvolver uma nova idéia.

\subsection{Discussão dos Resultados}

Ao realizar-se uma comparação antes e após a implantação da gestão de portfolio, nota-se uma alteração significativa. Primeiramente, cabe destacar que as decisões de desenvolvimento eram priorizadas somente conforme a visão da área de $\mathrm{P} \& \mathrm{D}$, utilizando critérios próprios da gerência funcional que, embora bem embasados, não refletiam as necessidades estratégicas da organização, em um sentido mais amplo. Após a restruturação, as decisões baseadas na gestão do portfolio, usando critérios tais como alinhamento

Quadro 1: Documentação nos Gates.

\begin{tabular}{|c|c|}
\hline Estágio/Gate & Itens \\
\hline \multirow{2}{*}{$\begin{array}{c}\text { Proposta } \\
\text { Básica/Gate } 1\end{array}$} & Objetivo do projeto; Especificação de desempenho do produto; Tipo de produto/negócio alvo \\
\hline & $\begin{array}{l}\text { Resultado da avaliação; documentos de referência; confirmação dos dados de entrada (revisão 0); gerente } \\
\text { do projeto indicado; recursos alocados }\end{array}$ \\
\hline $\begin{array}{c}\text { Planejamento do } \\
\text { Projeto/Gate } 2\end{array}$ & Resultado da avaliação; documentos de referência; confirmação dos dados de entrada (1ª revisão) \\
\hline \multirow{2}{*}{$\begin{array}{c}\text { Fase } \\
\text { Teste } 1 / \text { Gate } 3\end{array}$} & Resultado da avaliação; documentos de referência; confirmação dos dados de entrada (2ª revisão) \\
\hline & $\begin{array}{l}\text { Descrição final do produto; indicadores técnicos; indicadores industriais; indicadores financeiros; dados de } \\
\text { entrada } x \text { dados de saída }\end{array}$ \\
\hline $\begin{array}{c}\text { Fase } \\
\text { Teste 2/Gate } 4\end{array}$ & Resultado da avaliação; documentos de referência; confirmação dos dados de entrada (3a rev.) \\
\hline
\end{tabular}


estratégico, nível tecnológico, grau de dificuldade, retorno do investimento, dentre outros, trouxeram maior facilidade na tomada de decisão sobre que produtos deveriam ser desenvolvidos.

trouxe maior rigor na seleção de projetos para desenvolvimento de novos produtos da empresa estudada.

Outro aspecto que merece destaque é referente à relação entre as decisões de implantação com o que é estabelecido na teoria, principalmente considerando os trabalhos de Clark e Wheelwright (1993), Cooper (1993), Griffin e Page (1996) e Cooper et al. (1998), além dos princípios do PMBoK do PMI (2000). $\mathrm{O}$ alinhamento com esse referencial proporcionou uma estreita ligação entre o quadro teórico e o trabalho de campo, embora com as limitações inerentes a um estudo de caso único. Nes-

Houve uma mudança significativa na maneira como o desenvolvimento de novos produtos era conduzido na empresa estudada. Essa alteração envolveu tanto a perspectiva estratégica (no caso da gestão de portfolio) quanto a perspectiva operacional (na condução dos projetos durante o desenvolvimento e na organização da equipe de desenvolvimento). As particularidades de cada projeto no portfolio (em relação aos critérios de alinhamento estratégico, nível tecnológico, grau de dificuldade, retorno do investimento, etc.) passaram a conduzir a escolha dos projetos adequados para entrarem na fase de desenvolvimento. O desenvolvimento passou a ser mais bem estruturado, com uma forte ênfase no planejamento estratégico de produtos, como estabelecido por Rozenfeld et al. (2006). Adicionalmente, a prática da gestão de portfolio se sentido, novos trabalhos são necessários para corroborar (ou não) os pontos relevantes na implementação da gestão de portfolio. É importante destacar que não foram identificados conflitos significativos em relação à literatura.

Embora não seja um ponto central no desenvolvimento do trabalho de pesquisa, observam-se resultados importantes para a própria empresa. Para demonstrar essa importância, a empresa contava com 64 pessoas envolvidas nas equipes de projeto na ocasião do estudo, correspondendo a quase $70 \%$ do pessoal especializado, diretamente envolvido com projetos de novos produtos. Houve ainda um aumento no percentual da receita, em um período de três anos, contribuindo com quase $30 \%$ do faturamento de produtos desenvolvidos nesse período.

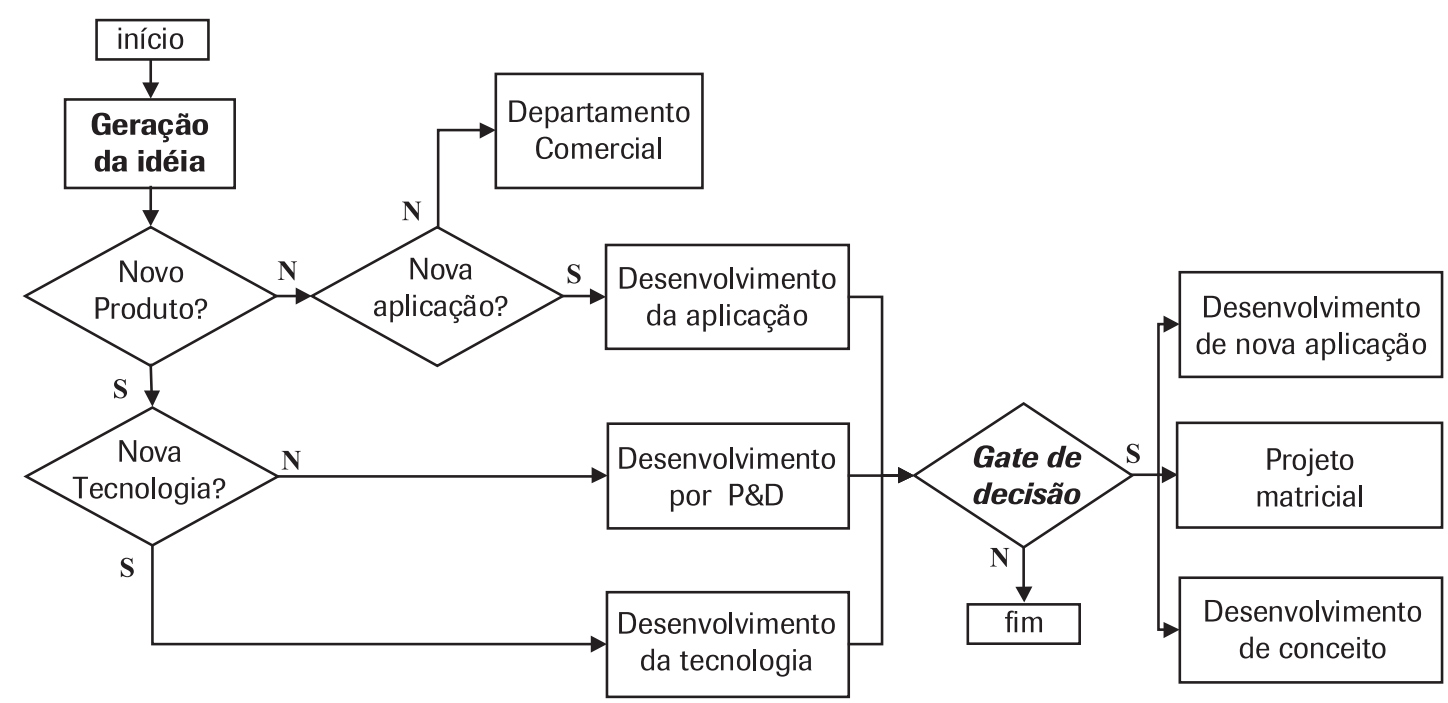

Figura 11: Fluxograma para decisão do tipo de desenvolvimento de produto. 


\section{CONCLUSÕES}

De uma maneira mais geral, o trabalho demonstrou a existência de uma prática relevante em gestão de portfolio, com lastro na teoria vigente possibilitando a obtenção de resultados positivos nas perspectivas estratégica e operacional. Na perspectiva estratégica, a empresa pode aplicar os conceitos de seleção de projetos, alinhada com suas necessidades estratégicas, por meio da implantação realizada. As bases dessa implantação mostraram-se viáveis sob o ponto de vista empírico e, como já citado, fortemente baseada no quadro teórico. Obviamente, algumas oportunidades para melhoria existem, uma vez que a empresa ainda não tem maturidade na adoção da gestão de portfolio e, portanto, serão necessários mais ciclos de aplicação para uma avaliação mais precisa. Nesse sentido, uma possibilidade para continuação desse estudo seria uma investigação longitudinal, em um período de médio prazo, após a implantação, para verificar a continuidade da prática da gestão de portfolio e os resultados decorrentes da experiência acumulada.

Na perspectiva operacional, a implementação auxiliou na seleção dos projetos, proporcionando maior facilidade e exatidão na tomada de decisão. Embora não tenha sido abordada neste trabalho, essa decisão auxiliou na alocação dos recursos para a condução dos projetos. Obviamente, essa última afirmação não é conclusiva do presente trabalho. Nesse sentido, uma das possibilidades para desenvolvimentos futuros é investigar a relação entre a gestão de portfolio e o desenvolvimento, no sentido de aferir o resultado dos projetos com as previsões da carteira de desenvolvimento.

Assim, considera-se que o presente trabalho alcançou os objetivos propostos, contribuindo para o endereçamento da questão da pesquisa, trazendo uma contribuição científica em uma perspectiva empírica por meio da demonstração da implementação da gestão de portfolio e suas implicações para a perspectiva operacional no desenvolvimento de novos produtos. No entanto, em função da limitação de caso único no presente trabalho, as possibilidades de generalização dos resultados são significativamente reduzidas. Visando a continuidade da investigação neste tema, e de modo a identificar insights, proposições e hipóteses, o passo seguinte é a ampliação na quantidade de casos de maneira a estender a contribuição científica do estudo.

\section{Artigo recebido em 03/12/2007 Aprovado para publicação em 04/03/2008}

\section{REFERÊNCIAS}

ANDRADE, M. M. Como Preparar Trabalhos para Cursos de Pós-graduação: Noções Práticas. São Paulo: Atlas, 2002.

CHENG, L. C. Caracterização da Gestão de Desenvolvimento do Produto: Delineando o seu Contorno e Dimensões Básicas. Anais do /l Congresso Brasileiro de Gestão de Desenvolvimento de Produto, São Carlos, $\mathrm{p}$. 1-9, 2000.

CLARK, K. B.; WHEELWRIGHT, S. C. Managing New Product and Process Development. The Free Press, New York, 1993.

COOPER, R. Winning at New Products Accelerating the Process from Idea to Launch. Perseus Books: Cambridge, 1993.

COOPER, R. et al. Portfolio Management for New Products. Addilson-Wesley Publishing: Reading, 1998.
COOPER, R.; EDGETT, S. J.; KLEINSCHMIDT, E.J. Portfolio Management in New Product Development: Lessons from the Leaders - I. Research-Technology Management, v. 40, n. 5, p. 16-28, 1997a.

Portfolio Management in New Product Development: Lessons from the Leaders - II. Research Technology Management, v. 40 , n. 6 , p. 43-52, 1997 b.

COOPER, R.; EDGETT, S. J.; KLEINSCHMIDT, E. J. New Problems, New Solutions: Making Portfolio Management more Effective. Research Technology Management, v. 43, n. 2, p. 18-33, 2000.

DANILA, N. Strategic Evaluation and Selection of R\&D Projects. R\&D Management, v. 19, n. 1, p. 47-62, 1989.
DOOLEY, L.; LUPTON, G.; O'SULLIVAN, D. Multiple Project Management: a Modern Competitive Necessity. Journal of Manufacturing Technology Management, v. 16, n. 5, p. 466482, 2005.

DUNCAN, W. R. A Guide to the Project Management Body of Knowledge. Pennsylvania: Project Management Institute Publications, 1996.

FONSECA, A. V. M.; ANDERY, P. R. P. Considerações sobre Sistema de Medição orientado ao Desenvolvimento de Produtos e Gerenciamento de Projetos. CD ROM do $3^{\circ}$ Congresso Brasileiro de Gestão de Desenvolvimento de Produtos, Florianópolis, 2001.

GUNASEKARAN, A. An Integrated Product Development-Quality Management System for Manufacturing. The TQM Magazine, v. 10, n. 2, p. 115-123, 1998. 
GRIFFIN, A. PDMA Research New Product Development Practices: Updating Trends and Benchmarking Best Practices. Journal of Product Innovation Management, v. 14, p. 429-458, 1997.

GRIFFIN, A.; PAGE, A. PDMA Success Measurement Project: Recommended Measures for Product Development Success and Failure. Journal of Product Innovation Management, v. 13, p. 478-496, 1996.

MARSON, A. O Papel do "Project Office" no Desenvolvimento de Produtos. CD ROM do $4^{\circ}$ Congresso Brasileiro de Gestão de Desenvolvimento de Produtos, Gramado, 2003.

MEYER, M. H. Revitalize your Product Lines through Continuos Platform Renewal. Research Technology Management, v. 40, n. 2, 1997.

MORAES, R. O.; LAURINDO, F. J. B. Um Estudo de Caso da Gestão de Portfolio de Projetos de Tecnologia de Informação. Gestão \& Produção, v. 10, n. 3, p. 312-328, 2003.

NASCIMENTO, P. T. S.; MARX, H. O Sistema de Inovação da Natura. Seminários em Administração, v. 5, São Paulo: USP, 2001.
Disponível em: <http://www.ead.fea.usp.br/ Semead/Vsemead/Operações.htm>. Acesso em: 9 dez. 2004

PETERS, A. J. et al. New Product Design and Development: A Generic Model. The TQM Magazine, v. 11, n. 3, p. 172-179, 1999.

PHILLIPS, R. et al. A Comparative Study of Six Stage-gate Approaches to Product Development. Integrated Manufacturing Systems, v. 10, n. 5, p. 289-297, 1999.

PMI - Project Management Institute. Guide of Project Management Body of Knowledge PMBoK, 2000 (PMI Minas Gerais), v. 1.0 (versão em português). Disponível em: <http://www. pmimg.org.br>. Acesso: 02 de fev. de 2004.

RABECHINI JÚNIOR, R.; MAXIMIANO, A. C. A.; MARTINS, V. A. A Adoção de Gerenciamento de Portfolio como uma Alternativa Gerencial: 0 Caso de uma Empresa Prestadora de Serviço de Interconexão Eletrônica. Revista Produção, v. 15 , n. 3, p. 416-433, 2005

RAHMAN, S. Product Development Stages and Associated Quality Management Approaches. The TQM Magazine, v. 7, n. 6, p. 25-30, 1995.
ROZENFELD, H.; FORCELLINI, F. A.; AMARAL, D. C.; TOLEDO, J. C.; SILVA, S. L., ALLIPRANDINI, D. H.; E SCALICE, R. K. Gestão de Deesenvolvimento de Produtos: Uma Referência para a Melhoria dos Processos. São Paulo: Saraiva, 2006.

SANTOS, C.; PASCHOARELLI, L. C. Análise do Programa de Desenvolvimento de Produtos Sandvik a partir da aplicação do "Funil" de Desenvolvimento. Anais Eletrônicos do II Simpósio de Engenharia de Produção - SIMPEP, Baurú, 1998.

TATIKONDA, M. V. An Empirical Study of Platform and Derivative Product Development Projects. Journal of Product Innovation Management, v. 16, p. 3-16, 1999.

VOSS, C.; TSIKRIKTSIS, N.; FROHLICH, M. Case Research in Operations Management. International Journal of Operations \& Production Management, v. 22 n. 2, p. 195-219, 2002.

YIN, R. K. Case Study Research - Design and Methods. Applied Social Research Methods Series, v. 5, London: Sage Publications, 1994.

\section{AGRADECIMENTOS}

O autor agradece ao apoio recebido do CNPq para a condução deste projeto de pesquisa, à empresa que permitiu que este estudo fosse realizado e também aos revisores da Revista Produção que contribuíram para o aperfeiçoamento do trabalho. 0 autor também agradece a Fundação Carlos Alberto Vanzolini pelo apoio concedido.

\section{SOBRE O AUTOR}

Paulo A. Cauchick Miguel

Departamento de Engenharia de Produção

Escola Politécnica, USP

End.: Av. Prof. Almeida Prado, trav. 2, o 128 - Cidade Universitária - 05508-090 - São Paulo - SP

E-mail: paulo.miguel@poli.usp.br 